\title{
Environmental Impact Assessment in higher education and training in Portugal
}

\author{
Tomás B. Ramos ${ }^{\mathrm{a}, *}$, Teresa Cecílio ${ }^{\mathrm{b}}$, João Joanaz de Melo ${ }^{\mathrm{a}}$ \\ ${ }^{a}$ New University of Lisbon, Faculty of Sciences and Technology, Department of Environmental Sciences and Engineering, \\ 2829-516 Caparica, Portugal \\ ${ }^{\mathrm{b}}$ University of the Algarve, Faculty of Marine and Environmental Sciences, Campus de Gambelas, 8005-139 Faro, Portugal
}

Received 2 November 2006; received in revised form 30 January 2007; accepted 17 February 2007

Available online 16 April 2007

\begin{abstract}
Environmental Impact Assessment (EIA) education has been a reality for years in many graduate and undergraduate programs worldwide. As EIA has grown as a widely accepted environmental policy tool, several professions have tried to incorporate these skills into their academic training. The main aim of this research was to assess the Portuguese profile of EIA education, measuring the degree of EIA integration in graduate and undergraduate programs. This paper intends to contribute to an understanding of the key factors related to EIA education. A national survey was conducted to obtain data on EIA education programs. More recently, many other programs, both graduate and undergraduate, have established EIA courses. New knowledge, practices, legislation and public policies are fundamental drivers of the application of EIA, which will probably continue to expand to more undergraduate and graduate programs. The association of EIA with other environmental management tools, such as environmental management systems or environmental performance evaluation, and sustainable development initiatives will be a priority challenge for all who are engaged in this domain.
\end{abstract}

Keywords: Environmental Impact Assessment; Education; Undergraduate and graduate programs

\section{Introduction}

Environmental Impact Assessment (EIA) was introduced in the United States of America in 1969 with the US National Environmental Policy Act (NEPA). In 1973, the European Economic Community (EEC) included EIA in its first Framework Program for the Environment, which later gave way to Directive 85/337/EEC. NEPA states that federal agencies are required to make analyses of environmental effects of implementing their programs or actions. As so, EIA in the US legislation was imposed upon the federal government for its projects and not for those of the private sector. On the other hand, the European Community Directive on EIAs applies to public and private projects which are expected to have

\footnotetext{
* Corresponding author. Tel.: +351 212948397; fax: +351212948554.
}

E-mail address: tabr@fct.unl.pt (T.B. Ramos). significant impacts on the environment. Projects to which the Directive applies are identified into two main list types of projects for which EIAs are required.

Since then, EIA has spread throughout the world and has become an important tool in ensuring that environmental values are considered within planning [1]. EIA systems have been established in many countries, either through legislation or through regulations or guidelines, although there are still countries where an EIA process has not been implemented, as mentioned by Glasson et al. [2] and El-Fadl and El-Fadel [3]. Some nations, e.g. Canada, Germany and the Netherlands, have a more developed EIA system, whereas in others the EIA process has only recently been implemented.

Portuguese EIA practice began in the early 1980s, on an informal and ad hoc basis. However, transposition of the EEC Directive and systematic EIA procedures only came about in 1990, with Decree-Law No. 186/90. Directive 85/337/EEC was later amended by Directive 97/11/EC. This was in turn 
transposed into Portuguese law by Decree-Law No. 69/2000, which was amended by Decree-Law No. 197/2005.

Others types of impact assessment, e.g. social impact assessment, health impact assessment, risk assessment and strategic environmental assessment (SEA) of policies, plans and programs, have increased significantly in recent years. In 2001, the European Union (EU) created Directive 2001/42/ EC on strategic impact assessment; this came into force in 2004 but has not yet been transposed into local law in some member states, including Portugal.

The worldwide increase in the number of projects requiring EIA has entailed a great demand for EIA professionals with the appropriate skills. In addition, EIA education has been a reality for years in many graduate and undergraduate programs worldwide. As EIA has grown as a widely accepted environmental policy tool, several professions have tried to incorporate these skills into their academic training. Countries that have been implementing EIA for the longest time have similar EIA processes, but the participants' skills and EIA document quality are quite variable due to different forms of education and learning processes, as is stated by Lundström and Olausson [4].

It is well established that an improvement in EIA document quality is quite dependent on the legal context and improved experience. However, specific training appears to be important in determining the quality of EIA reports [5]. Various problems identified in EIA practice throughout the world are related to a general lack of understanding of EIA concepts and practice among EIA participants [5,6].

EIA training has increased significantly in recent years and several training courses and materials have been prepared (e.g. [7,8]). Nevertheless, these courses have reached only a very small percentage of the potential population needing such courses [6]. They incorporate different curricula, according to the training institution, and emphasize different aspects. Lundström and Olausson [4] stated that one way to handle this difficulty is to improve EIA education at various levels, namely, non-university and pre-university education, technology training and undergraduate and graduate programs.

There is a dearth of scientific literature on the topic of EIA education, though some work has been carried out, such as Wood [9] or Lundström and Olausson [4], but the main part particularly relates to general recommendations on training activities.

The main objective of this research was to assess the Portuguese profile of EIA education, with an appraisal of the degree of EIA integration into graduate and undergraduate programs, as an initial contribution to an understanding of the key factors related to EIA education and training.

\section{EIA in Portuguese undergraduate and graduate programs}

Data on EIA education programs were obtained from a national survey. The aim of the survey was to evaluate the integration of EIA into graduate and undergraduate programs in Portuguese universities and polytechnic institutes.

A pre-selection process was conducted among the 349 Portuguese higher education institutions identified. Only institutions offering natural science, technology, engineering, architecture, environmental management, geography and planning programs were used to derive the education institutions statistical population. A total of 75 schools were thus preselected, representing public and private institutions offering programs at undergraduate and/or graduate levels.

The survey was conducted at the beginning of 2005 in those 75 institutions (universities and polytechnic institutes). The research survey examined a variety of sources, including institutional web pages, government publications, environmental agency reports and academic papers. From this survey, 37 higher education institutions with EIA courses were encountered (Table 1).

In those 37 institutions, 86 programs with EIA courses were identified. Of those, 73 were undergraduate level and 13 graduate level. To better manage and convey the results, the programs were grouped together according to their similarities (Table 2).

The results show that EIA courses are especially present in environmental engineering, civil engineering and environmental management programs, representing, respectively, $29 \%$, $20 \%$ and $9 \%$ of the programs that have this field of study (Table 3). In the national context, there are about 25 environmental engineering programs and 34 civil engineering programs. Thus, according to the survey conducted, EIA courses are present in all environmental engineering programs and in $50 \%$ of civil engineering programs.

Environmental engineering is a relatively new component in the Portuguese higher education scenario. Undergraduate programs in environmental engineering started in 1977, with the first class graduating in 1982; these are the ones that have the longest history of including EIA. At the international level, many environmental engineering programs include a compulsory course on impact assessment at the undergraduate level and an optional course at the graduate level, as identified by Smith and Biswas [10] in Canada.

More recently, in the 1990s, classical programs such as civil engineering, when submitted to reform, added new courses, including some on EIA. Furthermore, some newer programs such as oceanography also propose EIA as a mandatory course. One can observe different responses to the inclusion of environmental issues into various scientific fields.

Table 1

Higher education institutions surveyed

\begin{tabular}{lll}
\hline & Institution & \\
\cline { 2 - 3 } & Surveyed & With EIA courses \\
\hline Universities & 29 & 23 \\
Polytechnic institutes & 46 & 14 \\
Total & 75 & 37 \\
\hline
\end{tabular}


Table 2

Programs aggregated by technical field

\begin{tabular}{|c|c|}
\hline Individual program & Program group \\
\hline $\begin{array}{l}\text { Agronomic engineering } \\
\text { Forest engineering } \\
\text { Zootechnical engineering }\end{array}$ & Agronomic engineering \\
\hline $\begin{array}{l}\text { Environmental engineering } \\
\text { Engineering and environmental } \\
\text { management } \\
\text { Environmental and natural } \\
\text { resources engineering } \\
\text { Environmental and territorial } \\
\text { engineering } \\
\text { Natural resources and } \\
\text { environmental engineering }\end{array}$ & Environmental engineering \\
\hline $\begin{array}{l}\text { Civil engineering } \\
\text { Civil and environmental engineering } \\
\text { Civil engineering and land } \\
\text { use management }\end{array}$ & Civil engineering \\
\hline Chemical engineering & Chemical engineering \\
\hline $\begin{array}{l}\text { Biophysical engineering } \\
\text { Food industry engineering } \\
\text { Hydrological resources engineering } \\
\text { Territorial engineering }\end{array}$ & Other engineering categories \\
\hline $\begin{array}{l}\text { Architecture } \\
\text { Landscape architecture }\end{array}$ & Architecture \\
\hline $\begin{array}{l}\text { Environmental management } \\
\text { Environmental and territorial } \\
\text { management } \\
\text { Management and environmental control } \\
\text { Management and nature conservation }\end{array}$ & Environmental management \\
\hline $\begin{array}{l}\text { Forest resources and the environment } \\
\text { Environmental sciences } \\
\text { Environmental technologies } \\
\text { Hydraulic and hydrological } \\
\text { resources and the environment } \\
\text { Sciences and environmental technologies } \\
\text { Energy and the environment }\end{array}$ & Environmental sciences \\
\hline $\begin{array}{l}\text { Geography and territorial management } \\
\text { Geography and regional development } \\
\text { Geography } \\
\text { Geography and planning }\end{array}$ & Geography \\
\hline $\begin{array}{l}\text { Environmental health } \\
\text { Biology } \\
\text { Oceanography } \\
\text { Planning and sustainable } \\
\text { project construction } \\
\text { Civil protection }\end{array}$ & Other \\
\hline
\end{tabular}

There are various influences that can explain EIA inclusion in revised undergraduate and graduate programs:

1. environmental legislation and public policies;

2. new knowledge and practice related to a general trend of environmental integration; and

3. the market demand for environmentally trained or at least environmentally aware professionals, which means that the market plays an important role in the development of EIA education.
Table 3

EIA courses in Portuguese higher education institutions

\begin{tabular}{lll}
\hline Program group & $\begin{array}{l}\text { Absolute frequency } \\
\text { (number) }\end{array}$ & $\begin{array}{l}\text { Relative } \\
\text { frequency (\%) }\end{array}$ \\
\hline Engineering & & 29 \\
$\quad$ Environmental & 25 & 20 \\
Civil & 17 & 3 \\
Chemical & 3 & 6 \\
$\quad$ Agronomic & 5 & 6 \\
Others & 5 & 9 \\
Environmental management & 8 & 5 \\
Architecture & 4 & 7 \\
Environmental sciences & 6 & 6 \\
Geography & 5 & 9 \\
Others programs & 8 & \\
\hline
\end{tabular}

The environmental or "green" market has grown significantly during the last decades throughout Europe and the rest of the world. After the European EIA directive was published in 1985, impact assessment became important to environmental professionals and decision-makers. For years, EIA has been a major source of employment for Portuguese environmental engineers, giving a signal to other environmentrelated professions.

Most EIA courses are organized as a separate semester discipline (in about $87 \%$ of the programs). Some have the subject of EIA integrated into broader environmental courses, such as "environmental engineering" or "environmental management". A few programs include more than one course on EIA, sometimes optional. This takes place in civil engineering related programs, where courses such as civil engineering and the environment and environmental management also include EIA components, in addition to the specific course on impact assessment. In some cases, this fact could reflect some misunderstanding of the role of EIA as an autonomous tool, assuming that this scientific domain represents, rather, an introduction to environment-related issues, useful for professions that are not specialized in environment issues. Nevertheless, in the civil engineering context EIA as a mandatory issue is certainly related to the requirements for an EIA process on most major civil engineering projects such as roads, airports, marinas, harbours, railways and dams.

The workload of the majority of EIA undergraduate courses ranges from 4 to $5 \mathrm{~h}$ /week in total (lectures and practical classes, excluding assignments and project work). If we compare environmental engineering and civil engineering programs, the workload of EIA courses at different universities presents a considerable range of variation. These data are generally not available at the graduate level.

Overall lecture classes have a similar range among the different programs, with a majority involving an average of $2 \mathrm{~h} /$ week. However, within similar programs there are wide differences, ranging from 0 to $3 \mathrm{~h} /$ week for the environmental engineering program groups. Practical classes present a similar pattern, with a majority involving an average of $2-3 \mathrm{~h} /$ week, despite a great difference among courses of $0-6 \mathrm{~h} /$ week (Table 4). The programs that have $0 \mathrm{~h} /$ week of lecture classes have a combined scheme of lectures/practical classes. 
Table 4

Work load of EIA courses by undergraduate program group

\begin{tabular}{|c|c|c|c|c|c|c|}
\hline \multirow[t]{2}{*}{ Program group } & \multicolumn{3}{|c|}{ Lecture classes (h/week) } & \multicolumn{3}{|c|}{ Practical classes (h/week) } \\
\hline & Average & Max & Min & Average & Max & Min \\
\hline Architecture & 2 & 2 & 0 & 3 & 5 & 5 \\
\hline Agronomic engineering & 2 & 2 & 2 & 3 & 3 & 2 \\
\hline Chemical engineering & 1 & 3 & 0 & 2 & 3 & 2 \\
\hline Civil engineering & 2 & 3 & 0 & 2 & 2 & 0 \\
\hline Environmental sciences & 2 & 2 & 2 & 1 & 2 & 0 \\
\hline $\begin{array}{c}\text { Environmental } \\
\text { engineering }\end{array}$ & 2 & 3 & 0 & 3 & 6 & 2 \\
\hline $\begin{array}{l}\text { Other categories } \\
\text { of engineering }\end{array}$ & 2 & 2 & 2 & 2 & 2 & 2 \\
\hline Other programs & 2 & 3 & 2 & 2 & 3 & 2 \\
\hline Total & 2 & 3 & 0 & 2 & 6 & 0 \\
\hline
\end{tabular}

These results of the work load in EIA courses may reveal different perspectives on managing this course with regard to scope, the importance to the program objectives and targets, training methods and contents. Also the academic background and practical EIA experience of the lecturer in charge generally have a significant influence on the overall course profile.

These differences among the workload of similar EIA courses may contribute to inadequate training in EIA, leading to various EIA skills within the same professional category or level. However, to explore the specific contents and workload of different classes in greater detail, new data need to be obtained. This constraint is particularly valid at the moment, when several changes in the Portuguese education system are being implemented, mainly related to adapting programs to the Bologna Process.

A qualitative analysis of EIA course content to the surveyed data was also carried out for the courses with a table of contents available on the Internet ( 24 of the 84 surveyed). A division was made between common and uncommon subjects in the course content.

The results were not unexpected and may indeed explain certain insufficiencies in the performance of some EIA professionals and the related EIA processes.

All or nearly all EIA courses covered the more traditional issues, with varying degrees of emphasis:

basic concepts such as sustainable development and EIA principles and history;

- EIA processes, including national and international legislation, actors and products;

- EIA techniques such as screening, scoping, baseline and impact identification;

- EIA structure, content and methodology;

- basic impact prediction and mitigation techniques; and

- monitoring and/or auditing.

Other newer and more difficult or specialized issues were seldom covered:

- use of environmental indicators and communication;

- public participation;
- review, evaluation and decision support;

- social, health and economic impact assessments;

- risk assessment; and

- strategic environmental assessment.

Health impact assessment should be stressed as a domain that is absent in all the EIA courses reviewed. Traditionally, environmental and health related issues are not treated together by the environmental agencies and departments, despite some recent efforts to fill this gap. Additionally, European and national regulations do not emphasize this theme. However, it should be underlined that joint environmental and health impact assessment are not really a new issue, despite their infrequent presence in EIA training initiatives. For example, Bisset and Tomlinson [11] already mentioned the importance of this topic as a major focus on EIA training courses.

This research shows that many EIA courses need to be improved and updated, introducing certain important aspects of EIA. Issues like EIA follow-up (monitoring, auditing and environmental management) or social impact assessment are poorly stressed, with just certain general guidelines in the national and European EIA legislation being presented. A comprehensive introduction to EIA with an emphasis on impact identification, prediction and assessment, mitigation, communication, public participation, decision support and follow-up should be a priority of all EIA courses. Additionally, the European Commission [12] advises Member States to make more widespread use of its existing guidance on screening, scoping, reviewing and cumulative impacts. There should also be more training, at national level in various countries, in the use of these quality control documents. Also of rising importance is SEA and its correlation with planning practice and with project EIA. International Association for Impact Assessment (IAIA) principles of "best practice" for EIA can be used as an introductory general support for EIA course content design and evaluation, as they set out what should be emphasised and guaranteed in the courses.

However, significant disparities among the various EIA courses may be acceptable in certain cases, since the degree of knowledge and specificity will be quite different for each type of program. For example, civil engineering programs show that they have a general overview of EIA, often as a small part of broader environment-related courses. In contrast, environmental engineering courses present a more exhaustive and specialized approach, always providing individual courses for one or more semesters and usually building on knowledge from previous courses on more specialized issues.

In Portugal, recent EIA legislation and guidelines, along with increased experience and training, have led to improvement in the quality of EIA reports. However, as stated in a study on performance evaluation for the EIA process, conducted by Wood et al. [5], further training and the dissemination of information about the EIA process are needed for all participants in the process. This study mentioned the need for EIA training for the competent Portuguese authority and consultancy staff, as a means of enhancing the quality of EIA reports. 
Beyond the scope of the current research, in recent years other non-graduate EIA training initiatives have been organized in Portugal, as short courses. However, while EIA training is provided in universities and in short courses, there remain deficiencies in the training of specialists, senior managers and other personnel, as already mentioned for the case of the US in the 1980s [9]. More targeted EIA training is now necessary, e.g. on-the-job EIA training courses, arranged for small and/or specific groups within particular organisations, as is also stressed by Wood et al. [5]. Particular training courses could also be arranged for authorities at local and regional levels in order to improve their understanding of the EIA process, regulations and guidelines and their practical application within the respective national system, as partially suggested by the European Commission [12].

\section{Future EIA education trends and recommendations}

In the near future EIA courses should be ready to integrate new challenges dealing with scientific development, globalization, market pressures and new technologies. They should also be able to respond to sustainability objectives, particularly those involving social responsibility and equity, economic efficiency and environmental and health protection.

Several emerging and recent environmental management tools are beginning to play an important role in overall economic activities and sector development. The integration of environmental and sustainable development considerations into policy sectors and economic activities is one of the most challenging targets at an international level. Tools such as environmental management systems, environmental audits, eco-labelling, environmental and sustainable development indicators, life cycle analysis, externalities assessment, environmental performance evaluation, sustainability reporting and corporate social responsibility should be viewed as fundamental challenges to establish synergies, integration advantages and the optimization of procedures in general and thus save resources and produce efficient outcomes.

Beyond public organizations, private sector activities are also beginning to realise the benefits of voluntary higher education and training in impact assessment and related issues. Environmental impacts cross all different kinds of economic activities and organizations, challenging managers to have trained/certified staff. Those employees should be able to deal with EIA processes and establish the integration with several other policy and environmental management tools, such as the above mentioned. Private and public organizations will demand actions to recycle and renew the original education of their personnel, becoming also an emergent priority issue for those concerned with EIA higher education and training.

The future of EIA education should be evaluated on the basis of various assumptions about the development of the driving forces behind EIA services. According to the study carried out by Smith and Biswas [10] for the environmental engineering field, certain market considerations can also be assumed in relation to EIA: (i) the global economy, the global market place for technical skills and the changes affecting communications will influence educational systems;

(ii) there is a need to develop an EIA educational process that produces professionals who can apply for positions and lead EIA services throughout the world;

(iii) life-long, self-directed learning (continuing education) is a fundamental requirement of the EIA professional; and

(iv) the application of the principles of public health and environmental protection will become more stringent.

EIA education and training should give priority to their expansion to developing countries where there is a significant lack of trained personnel in environmental issues, including EIA. Multilateral and bilateral cooperation programs should be developed with these countries and the more developed countries. The provision of effective and efficient EIA assistance for training and education is currently a big challenge to accomplish.

EIA education will probably continue their expansion to other graduate and undergraduate programs, in particularly non-specific environmental programs. This development will reflect the general increase in environmental integration awareness and market opportunities by several professionals' curricula.

This general trend will probably reveal more than an effective focus on EIA, as a subject, by academia, but an image strategy developed by the education institutions to respond to external pressures or market opportunities. For non-environmental professionals, EIA is viewed as a general package of environmental issues, and commonly associated with a well-known environmental "label". However, program coordinators will realize that for certain areas (e.g. chemical engineering, mechanical engineering, and biotechnological engineering) other environmental disciplines will be more appropriate than EIA. Examples of these courses such as environmental management audits and systems, life cycle assessment or cleaner production tools will be more appropriate for certain cases, if they need to choose one environmental subject.

In the field of EIA ethical and conduct problems commonly arise, since many processes are very complex, involving many different perspectives, with public and private pressures. Professionals will, therefore, be frequently tested and evaluated and they should be well trained to deal with these situations. Some of the principles presented by the IAIA Code of Ethics can be viewed, in a certain way, as general guidelines for EIA educational systems, as they state what EIA professionals should undertake themselves when offering their services. Additionally, several professional categories have their own codes of ethics. For example, in the case of engineers, the Portuguese Association of Engineers has a mandatory short course on professional ethics and conduct for the new members.

Accreditation of EIA consultants, as proposed by Wood et al. [5], as a measure to improve the quality of EIA reports, 
could also be an important step that has implications for impact assessment courses and programs. This kind of measure could have significant influence on market regulation, since in many cases there are several unqualified professionals who are members of EIA technical teams or, even worse, coordinate those studies. Exhaustive and specialized EIA training, always with individual courses for one or more semesters, building on knowledge from previous courses on other specialized environmental issues, should be a basic pre-condition to be included in the certification process.

Accreditation of EIA staff could also include procedures for conducting general quality assessment of EIA courses, based on predefined public performance indicators and course guidelines. Education institutions could then report their course performance when required. In many countries, including Portugal, undergraduate programs are frequently evaluated by external committees. This includes each specific course, for example, EIA. These processes analyse different aspects of the curriculum and educational resources, according to various predefined criteria. However, no specific EIA course evaluation has been conducted in Portugal.

As stressed by UNEP [7], in the general EIA training context, if EIA courses for undergraduate and graduate courses are to be effective, they should be designed to meet: (i) the requirements for improving EIA practice in a region or country; and (ii) the specific needs of the people who attend the course. However, for EIA course quality design and evaluation a specific framework should be used. This framework should be developed under a set of guidelines designed for this purpose, including various aspects, in particular:

- the purposes, aims, and approaches for each type of course (e.g. short training, undergraduate or graduate; focused on the environment or not);

- general course plans;

- basic principles;

- regional and/or country specificities;

- mandatory vs. optional contents;

- fundamental skills for teachers;

- a self-evaluation checklist and related criteria; and

- indicators for performance quality evaluation.

Lee and Dancey [13] established several training initiative targets that can be adapted and taken into account in existing EIA education. They include the need, in particular, to:

- focus on the needs of the staff in the principal organizations engaged in the EIA process;

- relate all the principal types of projects covered by EIA regulations, while paying particular attention to those which numerically are the most important and where current practice is most deficient;

- address all the principal assessment tasks, while paying particular attention to those being least satisfactorily performed at the present; these tasks include the assessment of impact significance, health impact assessment, assessment of alternatives and EIA follow-up; and a provide guidance on reviewing the quality of Environmental Impact Statements (EISs) and exercising quality control.

The design of EIA courses should be performed with particular attention not only to the more obvious aspects such as the overall program objectives, the target population and the country requirements and realities, but also to various other elements such as those mentioned above, which are fundamental items for success in EIA education.

\section{Conclusion}

This research showed that EIA is a well-established field of knowledge in Portuguese higher education institutions, recognized by the teaching staff and the market alike. EIA courses are particularly present in environmental engineering and civil engineering programs. Various influences could explain the inclusion of EIA into undergraduate and graduate programs: (i) environmental legislation and public policies; (ii) new knowledge and practice related to a general trend towards environmental integration; and (iii) the market demand for environmentally trained or at least environmentally aware professionals. The workload of EIA courses at different universities presents a considerable range of variation, which could contribute to inadequate EIA training. Nevertheless, differences among the various EIA courses may be acceptable, when programs have significantly different scope and objectives.

However, significant deficiencies can be detected in some courses, which may be attributed to three problematic areas:

- in some cases, it may be a problem of the teachers' inexperience or lack of knowledge with regard to more difficult issues (e.g. evaluation and public participation);

- in the case of courses intended for general information, there is the question of superficiality; this is understandable, but minimum requirements still have to be met; and - finally, emerging issues (e.g. health, risk or strategic assessment) are not included in EIA course content; in addition, national experience on those themes is indeed short.

From this significant sample and recent developments, it is to be expected that EIA will continue to expand to more and more programs. The challenge is no longer to advertise the relevance of the issue - that has already been understood by the market - but to promote better quality in basic training in higher education and periodic upgrading throughout the career of a professional. This is a field in constant mutation. Better qualified professionals in the field will contribute to improving EIA quality.

One issue that certainly merits consideration is the certification of EIA professionals, both to distinguish different levels of EIA training and to provide a degree of performance control. It should not be understood as a mandatory procedure, but rather as a voluntary qualification, an opportunity for improvement and a signal to the market. 


\section{References}

[1] Morris P, Therivel R. Methods of environmental impact assessment. 2nd ed. London: Spon Press; 2001.

[2] Glasson J, Therivel R, Chadwick A. Introduction to environmental impact assessment. 2nd ed. London: Spon Press; 1999.

[3] El-Fadl K, El-Fadel M. Comparative assessment of EIA systems in MENA countries: challenges and prospects. Environmental Impact Assessment Review 2004;24:553-93.

[4] Lundström S, Olausson I. The didactics of EIA [IAIA abstract volume]. In: International association for impact assessment conference, 24-30 April, Vancouver, B.C., Canada; 2004.

[5] Wood C, Barker A, Jones C, Hughes J. Evaluation of the performance of the EIA process. final report. In: Main report, vol. 1. Manchester: EIA Centre, University of Manchester Press; 1996.

[6] Morgan R. Progress with implementing the environmental assessment requirements of the resource management act in New Zealand. Journal of Environmental Planning and Management 1995;38:333-48.

[7] UNEP. Environmental impact assessment: training resource manual. 2nd ed. Geneva: United Nations Environment Programme; 2002.
[8] Ecaat J. Environmental impact assessment training resource manual. In: Jacobsen Ulrik, editor. Forum for energy and development/DANIDA fellowship programme; 2001. Denmark.

[9] Wood C. The Adequacy of training for EIA in the United States of America. Environmental Impact Assessment Review 1985;5(4): 321-37.

[10] Smith DW, Biswas N. Environmental engineering education in Canada. Journal of Environmental Engineering and Science 2002;1:1-7.

[11] Bisset R, Tomlinson P. EIA training courses organized by the centre for environmental management and planning, University of Aberdeen: an analysis of experience. Environmental Impact Assessment Review 1985;5(3):279-81.

[12] European Commission. Report from the Commission to the European Parliament and the Council on the application and effectiveness of the EIA Directive (Directive 85/337/EEC, as amended by Directive 97/11/ EC) - how successful are the Member States in implementing the EIA Directive. n.d.

[13] Lee N, Dancey R. The quality of environmental impact statements in Ireland and the United Kingdom: a comparative analysis. Project Appraisal 1993;1:31-6. 